\title{
New insights into the regulation of synaptic plasticity from an unexpected place: Hippocampal area CA2
}

\author{
Douglas A. Caruana, Georgia M. Alexander, and Serena M. Dudek ${ }^{1}$ \\ Laboratory of Neurobiology, National Institute of Environmental Health Sciences, National Institutes of Health, Research Triangle Park, \\ North Carolina 27709, USA
}

\begin{abstract}
The search for molecules that restrict synaptic plasticity in the brain has focused primarily on sensory systems during early postnatal development, as critical periods for inducing plasticity in sensory regions are easily defined. The recent discovery that Schaffer collateral inputs to hippocampal area CA2 do not readily support canonical activity-dependent long-term potentiation (LTP) serves as a reminder that the capacity for synaptic modification is also regulated anatomically across different brain regions. Hippocampal CA2 shares features with other similarly "LTP-resistant" brain areas in that many of the genes linked to synaptic function and the associated proteins known to restrict synaptic plasticity are expressed there. Add to this a rich complement of receptors and signaling molecules permissive for induction of atypical forms of synaptic potentiation, and area CA2 becomes an ideal model system for studying specific modulators of brain plasticity. Additionally, recent evidence suggests that hippocampal CA2 is instrumental for certain forms of learning, memory, and social behavior, but the links between CA2-enriched molecules and putative CA2-dependent behaviors are only just beginning to be made. In this review, we offer a detailed look at what is currently known about the synaptic plasticity in this important, yet largely overlooked component of the hippocampus and consider how the study of CA2 may provide clues to understanding the molecular signals critical to the modulation of synaptic function in different brain regions and across different stages of development.
\end{abstract}

Synaptic plasticity during postnatal brain development is critical for the experience-driven maturation of brain circuits. The neonatal visual system, in particular, is highly susceptible to disruptions in sensory experience, which can have profound effects on both the physiology and morphology of neurons in the developing visual cortex (Wiesel and Hubel 1965; Hubel et al. 1977). At any given point during maturation and development, and especially in the adult, synaptic plasticity varies significantly across many different brain areas. In the context of visual cortical plasticity (Wang and Daw 2003; Hooks and Chen 2007), layer IV appears to lose its capacity for synaptic modifications much earlier in development than the extragranular layers observed both in vivo (LeVay et al. 1980; Mower et al. 1985) and in vitro (Crair and Malenka 1995; Dudek and Friedlander 1996). Additionally, even in the CA1 region of the rodent hippocampus, which is renowned for the ease with which it supports induction of long-term synaptic potentiation (LTP) in both the adult and neonate (Barnes et al. 1996; Shankar et al. 1998; Malenka and Bear 2004), long-term synaptic depression (LTD) is much more robust in the neonate than in the adult (Dudek and Bear 1993). Comparing mechanisms of synaptic plasticity across brain regions is challenging, though, as principal neurons in the systems being compared often differ morphologically (i.e., neuronal phenotype) or physiologically (i.e., patterns of receptor and/or ion channel expression). Such subtle variations in neuronal physiology clearly have profound effects on the capacity to induce and sustain lasting synaptic modifications, and the identification of key regulatory genes, proteins, and signaling molecules continues to be essential toward understanding the mechanisms of synaptic plasticity in the mammalian brain. To this end, the traditional approach has been to first identify the key molecules required for synaptic potentiation or

\footnotetext{
${ }^{1}$ Corresponding author

E-mail dudek@niehs.nih.gov

Article is online at http://www.learnmem.org/cgi/doi/10.1101/lm.025304.111.
}

depression within a single brain region and, second, to determine whether these same molecules generalize to additional brain areas. More recently, the study of area CA2 in the hippocampus, a somewhat neglected region, has uncovered an array of novel and potentially critical signaling molecules that regulate synaptic function. Although principal cells in CA2 bear superficial resemblance to those in neighboring CA1 and CA3, CA2 pyramidal neurons are endowed with many unique physiological, molecular, and genetic characteristics that make them ideal candidates for assessing regional differences in molecular signals that modulate synaptic plasticity.

Early anatomical studies demonstrated area CA2 as being distinct from other hippocampal subfields (Ramón y Cajal 1902; Lorente de Nó 1934), yet CA2 pyramidal neurons are seldom included in circuit diagrams and schematic representations used to support many modern theories describing hippocampal function (van Strien et al. 2009). Indeed, area CA2 has traditionally been viewed as a "transition" zone situated between areas CA3 and CA1, sharing more in common anatomically with area CA3 than with any other region of the hippocampus (Lorente de Nó 1934; Woodhams et al. 1993; Ishizuka et al. 1995). Recent evidence, however, has shown that synapses onto pyramidal neurons in CA2 possess many unique characteristics not observed in either CA3 or CA1, and these findings only underscore the importance of reconsidering the role of hippocampal CA2 in learning and memory (Fig. 1A).

Considerable evidence indicates that, compared to neurons in other hippocampal subfields, CA2 pyramidal cells do have different morphological characteristics, intrinsic and extrinsic connections, biophysical and synaptic properties, and patterns of gene and protein expression. For example, the somata of neurons in CA2 are typically larger than those found in either CA 3 or CA1 (Mercer et al. 2007), and pyramidal cells in CA2 fall into one of several distinct categories based on the unique branching patterns of their apical dendrites (Bartesaghi and Ravasi 1999). Additionally, 
A

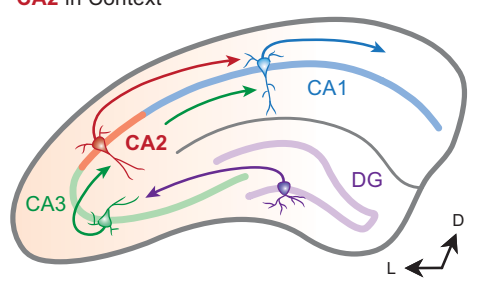

B

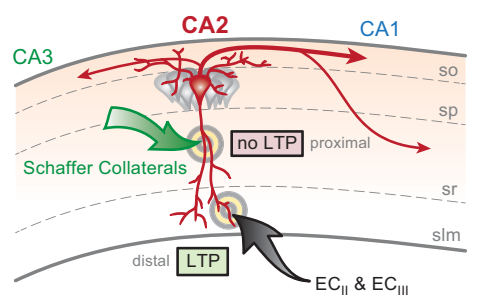

Figure 1. Hippocampal area CA2 is often excluded from circuit diagrams illustrating the flow of information through the hippocampus. $(A)$ The simplified schematic diagram is of a typical coronal section through the dorsal hippocampus and highlights how area CA2 (shown in red) fits within the traditional "trisynaptic" circuit. Arrows indicate the primary direction of information flow through the circuit (D, dorsal; $L$, lateral). Granule cells in the dentate gyrus (DG, purple) form synapses on pyramidal cells in area CA3 via the mossy fibers. In turn, CA3 neurons (green) synapse with neurons in both CA2 and CA1 (blue) via the Schaffer collaterals. CA2 pyramidal neurons project mainly to the stratum oriens of area CA1 and synapse onto the basal dendritic arbors of CA1 pyramidal cells. Note, CA2 axons also branch and project to the stratum radiatum in CA 1 , as well as the stratum oriens of proximal CA3, though these projections are less dense (shown in $B$ ). (B) Induction of activity-dependent LTP differs along the proximal-distal axis of CA2 pyramidal neurons. Schaffer collateral projections to the proximal dendritic compartment of CA2 neurons do not typically support activity-dependent LTP (green arrow, no LTP). This is in contrast to temporoammonic inputs from the entorhinal cortex to the distal dendrites of CA2 neurons which readily express LTP (black arrow, LTP). (so) Stratum oriens; (sp) stratum pyramidale; ( $\mathrm{sr}$ ) stratum radiatum; (slm) stratum lacunosum moleculare.

pyramidal neurons in CA2 receive prominent and selective inputs from the supramammillary nucleus of the hypothalamus (SuM) (Kocsis and Vertes 1994; Magloczky et al. 1994; Borhegyi and Leranth 1997). Although the purpose of this selective innervation is not entirely clear, it may play a role in memory consolidation by modulating hippocampal excitability (Pan and McNaughton 2004; Shahidi et al. 2004b). Area CA2 also receives direct excitatory inputs from both layers II and III of the entorhinal cortex (Chevaleyre and Siegelbaum 2010), and axons of CA2 pyramidal neurons preferentially target the basal dendritic arbors of neurons in CA1 (in the stratum oriens) (Mercer et al. 2007), though less dense collaterals project to the stratum radiatum in CA1 (Mercer et al. 2007) as well as to the stratum oriens in proximal CA3 (Tamamaki et al. 1988). The intrinsic electrophysiological properties of pyramidal neurons in CA2 differ significantly from those in CA1 (see discussion below), and these differences are maintained across several rodent species including the rat (Zhao et al. 2007), mouse (Chevaleyre and Siegelbaum 2010), and even the South American rodent, Proechimys (Scorza et al. 2011). Perhaps most striking, though, is the observation that a number of genes, including the regulator of G-protein signaling 14 (RGS14), Amigo2, PCP4, TARP5, FGF5, and several adenylyl cyclases (e.g., adcy1, adcy5, and adcy6), are highly expressed in CA2 (Lein et al. 2005, 2007). Moreover, both the adenosine $A_{1}$ receptor (Ochiishi et al. 1999) and the vasopressin $1 \mathrm{~b}$ receptor (Young et al. 2006) are highly enriched in CA2 pyramidal cells. Taken together, these findings dem- onstrate that area CA2 can be distinguished quite easily from other hippocampal subfields based on a number of structural, molecular, and physiological criteria. A reasonable hypothesis, therefore, is that area CA2 may selectively mediate some of the cognitive functions that have previously been ascribed to other hippocampal subfields. Conversely, the hippocampus may have been deemed unnecessary for some forms of learning and memory simply because area CA2, specifically, had been overlooked.

\section{The limited expression of 'typical' synaptic plasticity in area CA2}

Traditionally, the hippocampus has been regarded as a structure critical for the formation of new declarative memories, and it is widely accepted that LTP and LTD are cellular correlates underlying the formation, storage, and removal of memories in the hippocampus and, indeed, in other areas of the brain (Bliss and Lomo 1973; Morris et al. 1990; Dudek and Bear 1992; Abraham and Williams 2003; Lisman 2003; Malenka and Bear 2004; Massey and Bashir 2007). As might have been predicted based on the complement of genes expressed in CA2 (e.g., ptpn5 for STEP phosphatase) (Boulanger et al. 1995; Pelkey et al. 2002), synaptic plasticity in area CA2 differs dramatically from other hippocampal subfields in that Schaffer collateral (SC) projections originating from CA3 normally fail to support induction of activity-dependent LTP (Zhao et al. 2007; Figs 1B, 2A,B). This is in stark contrast to the same SC projections to area CA1 that quite readily express robust potentiation in response to a myriad of stimulus induction protocols (Fig. 2C,D). Initial studies demonstrated that SC inputs to area CA2 were incapable of supporting LTP following typical induction protocols effective in CA1: specifically, high-frequency $(100$ or $200 \mathrm{~Hz})$ afferent stimulation in current clamp mode or $3-\mathrm{Hz}$ stimulation paired with the depolarization of CA2 pyramidal cells to $0 \mathrm{mV}$ in voltage clamp mode (Zhao et al. 2007; Fig. 2A-D). Blockade of protein phosphatases with okadaic acid or using the perforated patch clamp technique to prevent dialysis of the intracellular milieu failed to permit induction of LTP (Zhao et al. 2007). Moreover, no measurable differences were detected between areas CA1 and CA2 in basal AMPA- or NMDA-mediated synaptic transmission, EPSC amplitudes, mEPSC frequencies and amplitudes, or paired-pulse facilitation that could account for the lack of activity-dependent LTP in area CA2. Importantly, induction of LTP in CA2 was still absent during separate experiments in which $\mathrm{GABA}_{\mathrm{A}}$-mediated transmission was blocked by picrotoxin (Zhao et al. 2007). These findings are significant because area CA2 has been shown to contain a particularly dense plexus of parvalbumin-positive axons (Pitkanen and Amaral 1993; Woodhams et al. 1993; Mercer et al. 2007), similar to what is seen in the later stages of development in visual cortex (Stichel et al. 1987).

The absence of LTP in SC inputs to CA2 had been predicted by Zhao et al. (2007) based on the high expression of TREK-1 and TREK-2 potassium channels in CA2 relative to other hippocampal subfields (Talley et al. 2001). Consistent with the high levels of mRNA for these channels in CA2, the intrinsic biophysical properties of CA2 pyramidal neurons were found to differ considerably from those in CA1, suggesting initially that differences in neuronal excitability alone might account for the lack of LTP in SC inputs to CA2. Specifically, CA2 neurons displayed greater potassium-mediated leak currents, and as a result, had significantly lower resting membrane potentials, required more depolarizing current to initiate action potential firing (rheobase current), and had a less negative threshold for generating action potentials relative to cells in CA1 (Zhao et al. 2007; Fig. 2E-H). These differences in intrinsic excitability alone failed to explain the lack of 
A Record in CA2

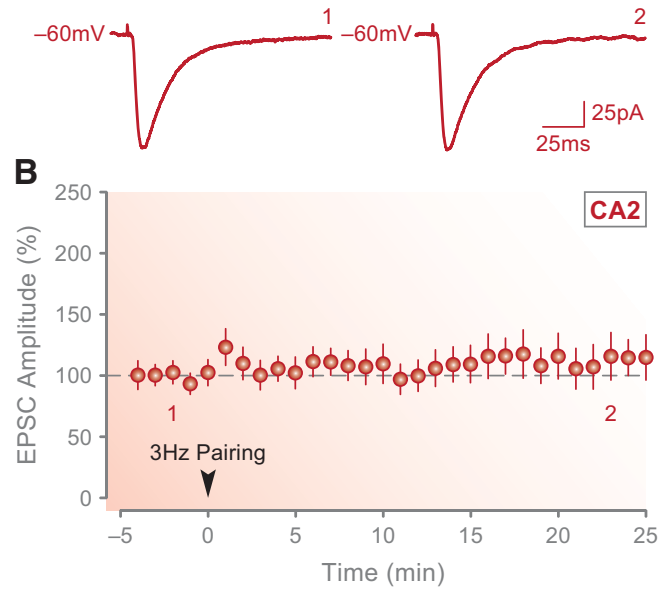

E

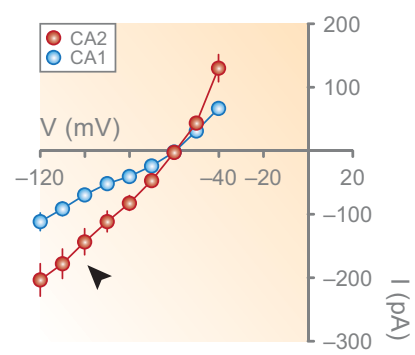

I

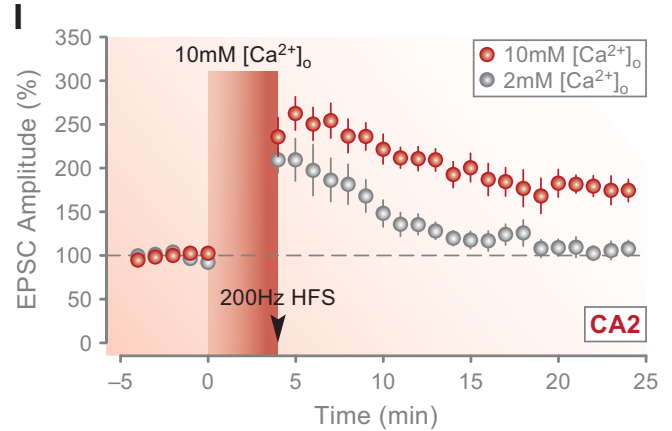

\section{Record in CA1}
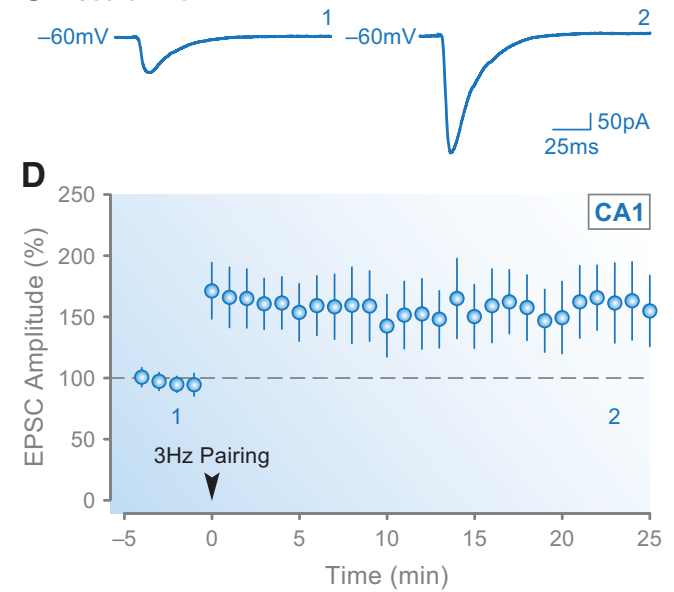

\section{$\mathbf{F}$}

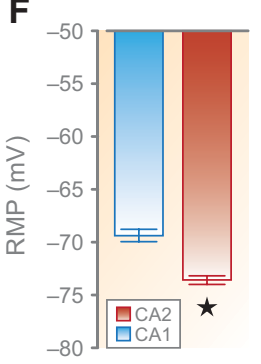

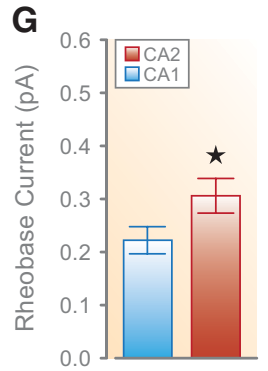

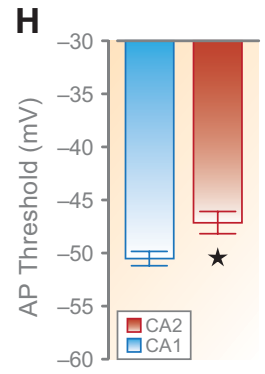

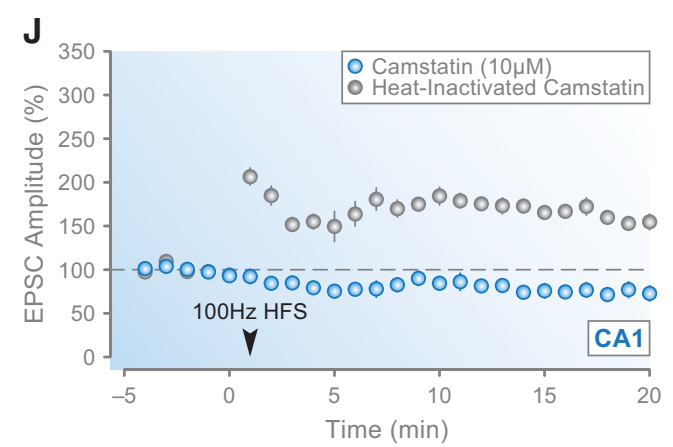

Figure 2. The lack of activity-dependent LTP at Schaffer collateral synapses in area CA2 is due mainly to robust calcium handling in CA2 pyramidal neurons. $(A, B)$ Pairing $3-\mathrm{Hz}$ afferent synaptic stimulation of the Schaffer collaterals with the depolarization of CA2 pyramidal cells to $0 \mathrm{mV}$ fails to induce activity-dependent LTP in area CA2. Group data in B show the averaged amplitudes of EPSCs (normalized to baseline) before and after the pairing protocol (arrow) to induce LTP in CA2 neurons. Bars indicate the mean \pm SEM in this and subsequent figures. Sample EPSCs shown in $A$ are from the time points marked by the corresponding numbers in $B .(C, D)$ In contrast, the same pairing protocol induces robust LTP in Schaffer collateral inputs to area CA1. The intrinsic biophysical properties of neurons in CA2 differ significantly from those in CA1. Relative to pyramidal cells in area CA1, CA2 pyramidal neurons show greater leak currents at holding potentials less than $-60 \mathrm{mV}$ (E, red circles, arrow), as well as have a lower resting membrane potential $(F$, red bar), higher rheobase current $(G$, red bar), and lower action potential threshold $(H$, red bar). Note, stars indicate $P<0.05$ in this and subsequent figures. Data modified from Zhao et al. (2007). Differences in intrinsic excitability alone, however, do not account for the lack of LTP in CA2 neurons (data not shown). CA2 pyramidal neurons display higher calcium buffering and extrusion relative to cells in CA1. (I) A temporary increase in the amount of extracellular calcium from $2 \mathrm{mM}$ (gray circles) to $10 \mathrm{mM}$ (red circles) for $3 \mathrm{~min}$ (indicated by the red bar) permits induction of LTP in CA2 pyramidal cells following tetanic stimulation ( $200 \mathrm{~Hz} \mathrm{HFS}$; arrow) of the Schaffer collaterals. ( $)$ Loading CA1 neurons with a functional analog of the calmodulin-regulating protein Pep-19 blocks induction of LTP (blue circles). Data modified from Simons et al. (2009).

activity-dependent LTP in CA2 neurons; the total number of action potentials fired and the amount of membrane potential depolarization observed during high-frequency tetanic stimulation did not differ between areas CA1 and CA2 (Zhao et al. 2007). More importantly, however, the inclusion of cesium in the recording pipette, which blocks potassium channels, failed to restore LTP at SC synapses in CA2. Additionally, no differences in spike accommodation following suprathreshold current injec- tion were observed between excitatory neurons in CA1 or CA2. Thus, like the case for synaptic inhibition, these results suggest that something other than apparent differences in intrinsic excitability were responsible for the lack of activity-dependent LTP in SC inputs to CA2.

Several mechanisms have now been identified as severely limiting activity-dependent LTP at SC synapses in CA2. As principal cells in CA2 are known to express high levels of some calcium- 
regulating proteins, including calbindin (Sloviter 1989; Leranth and Ribak 1991) and Pep-19 (Ziai et al. 1988), and because CA2 pyramidal neurons are insensitive to a variety of epileptiform-related insults, Sloviter (1989) hypothesized that CA2 neurons may have exceptionally robust calcium handling mechanisms. Because calcium signaling is critical for the induction of activity-dependent plasticity in other regions of the hippocampus (Lynch et al. 1983; Malenka et al. 1988), it followed that the resistance of SC inputs to support induction of LTP may reflect differences in local calcium handling in CA2. Using two-photon confocal imaging of dendrites and spines in CA2 pyramidal neurons loaded with a fluorescent calcium indicator dye, Simons et al. (2009) demonstrated that evoked calcium transients were significantly smaller in CA2 when compared to transients evoked in CA1 and CA3 under the same conditions: the average change in free calcium was only $227 \mathrm{nM}$ in CA2 spines vs. $1055 \mathrm{nM}$ and $1253 \mathrm{nM}$ for CA1 and CA3 spines, respectively. From these data, it was calculated that CA2 pyramidal neurons had a significantly higher endogenous calcium buffering capacity (by a factor of nearly four) relative to neurons in either CA1 or CA3, as well as a significantly higher rate of calcium extrusion (1235 $\gamma, \mathrm{s}^{-1}$ for CA2 vs. $343 \gamma, \mathrm{s}^{-1}$ and 417 $\gamma, s^{-1}$ for CA1 and CA3, respectively). Such tight regulation over local endogenous calcium in CA2 pyramidal cells could account for the lack of activity-dependent LTP observed in these neurons under basal conditions.

To determine whether the strict regulation of calcium in CA2 spines was the limiting factor that prevented induction of LTP, free calcium levels in CA2 spines were raised temporarily to match those observed in CA1 spines during tetanic stimulation. Indeed, a brief increase in the level of extracellular calcium from $2 \mathrm{mM}$ to $10 \mathrm{mM}$ or use of a calcium pump inhibitor permitted induction of LTP in CA2 to a magnitude similar to the potentiation observed in the same SC inputs to CA1 induced under normal recording conditions (i.e., $2 \mathrm{mM}$ calcium) (Simons et al. 2009; Fig. 2I). In addition, the calcium-dependent induction of LTP in CA2 also required activation of NMDA receptors, similar to area CA1. Together, these data indicated that CA2 pyramidal neurons possess the intracellular machinery required to support induction of NMDAR-dependent LTP, but that the higher calcium buffering and extrusion in CA2 neurons normally prevents such plasticity from occurring. Although CA2 neurons do not selectively express high levels of specific calcium pumps or exchangers relative to other regions in the hippocampus that could account for the increased rates of extrusion observed, they are highly enriched in the calmodulin-regulating protein Pep-19 (Gerendasy 1999; Kubota et al. 2008). Pyramidal cells in CA1 do not normally express high levels of Pep-19, but to test whether Pep-19 regulates calcium extrusion, Simons et al. (2009) introduced into CA1 neurons a functional analog of Pep-19, camstatin, which successfully produced a plasticity-resistant phenotype in CA1 similar to pyramidal neurons in CA2 (Fig. 2J). Taken together, the results strongly support the idea that the lack of LTP at the SC to CA2 synapse results primarily from higher endogenous levels of calcium buffering and extrusion in CA2 pyramidal neurons. Based on these data, we expect that similar mechanisms may limit the magnitude of LTP in cerebellar Purkinje neurons and in dentate gyrus granule neurons (via a Pep-19-mediated increase in calcium extrusion). Calcium-binding proteins have also been reported to increase during development in the visual cortex (Hendrickson et al. 1991); however, these proteins are likely concentrated in interneurons, similar to inhibitory cells in CA2 (Mercer et al. 2007).

In addition to the calcium-regulating mechanisms described above, recent findings implicate another CA2-enriched protein, RGS14 (Lee et al. 2010), as playing a critical role in modulating synaptic plasticity in area CA2. RGS14 belongs to the diverse fam- ily of RGS proteins that limit G-protein-mediated signaling by enhancing GTPase activity to accelerate hydrolysis of GTP to GDP at active $G_{\alpha}$ subunits (Vellano et al. 2011). Unique among the RGS proteins, RGS14 can integrate G-protein signaling with ERK/ MAP kinase pathways to inhibit growth factor receptor responses (Shu et al. 2010). Even so, the link between RGS14 and calcium signaling is not obvious, and so it comes as some surprise that robust LTP was observed at SC synapses in area CA2 in hippocampal slices prepared from mice lacking the full-length RGS14 protein. In contrast, little LTP was induced in SC inputs to CA2 in wildtype controls. Further, deletion of RGS14 had no effect on the ability to induce LTP at SC synapses in CA1 (Lee et al. 2010). Consistent with a role for RGS14 as a scaffold of the ERK/MAP kinase signaling pathway, in addition to its GTPase activity, Lee et al. (2010) found that a MEK inhibitor effectively prevented the LTP observed in RGS14 knockout (KO) mice, thus mimicking the plasticity-resistant phenotype typically observed in wild-type CA2 pyramidal neurons. Together, these findings suggest that, via its interactions with the ERK1/2 signaling cascade, RGS14 acts to limit induction and expression of synaptic potentiation in area CA2.

Not all forms of activity-dependent plasticity are absent at SC synapses in area CA2; short-term facilitatory mechanisms, although generally considered to be expressed presynaptically, are intact in area CA2 as demonstrated by the ability of SC synapses to exhibit both paired-pulse facilitation and some short-term post-tetanic potentiation (Zhao et al. 2007). More interesting, however, was the observation that low-frequency stimulation (e.g., $2 \mathrm{~Hz}$ for $7.5 \mathrm{~min}$ ) induced LTD in many, but not all, cases (Zhao et al. 2007). The mechanisms by which LTP is suppressed at SC synapses in CA2 while leaving LTD intact in many neurons is unknown but likely reflects the regulation of intracellular calcium in CA2 pyramidal neurons (Simons et al. 2009). It may be argued, however, that lower levels of intracellular calcium, with perhaps a wider range (Feldman 2000), may be sufficient to induce LTD in CA2 as opposed to LTP. This is supported by the observation that LTD was occasionally induced in CA2 following highfrequency tetanic stimulation of SC inputs (Zhao et al. 2007), as well as in CA1 neurons loaded with camstatin (Simons et al. 2009). These results clearly demonstrate that some types of activity-dependent plasticity are supported at SC synapses in area CA2 and suggest that heterogeneity in the expression of plasticity may be a feature of CA2 pyramidal neurons. Additionally, inputs from layers II and III of the entorhinal cortex that form synapses onto the distal apical dendrites of CA2 pyramidal cells are surprisingly highly plastic (Chevaleyre and Siegelbaum 2010; Fig. 1B). This property is notable because CA2 is the only region of hippocampus in which afferents originating from projection neurons in both layer II and layer III of the entorhinal cortex terminate, suggesting that the entorhinal cortex may powerfully control the output of CA2 neurons. Such regulation of CA2 output by the entorhinal cortex may have important implications for downstream targets of CA2, mainly pyramidal cells located in area CA1 (Chevaleyre and Siegelbaum 2010; Piskorowski and Chevaleyre 2012).

\section{Another layer (or two) of plasticity regulation in CA2}

Given the apparent lack of LTP and variability associated with induction of LTD at SC synapses in area CA2, one might conclude that CA2 is a highly stable component of the hippocampal circuit, with little part to play in the more plastic functions of the hippocampus. However, the high expression of specific genes and proteins in area CA2 that have been linked to cognitive 
function and to certain social behaviors argues against this conclusion (Wersinger et al. 2002; Prediger and Takahashi 2005; DeVito et al. 2009). Additionally, recent work illustrates that SC inputs to CA2 are, in fact, highly plastic provided that the correct "stimulus" is applied. For example, the relatively high expression patterns for both the vasopressin $1 \mathrm{~b}$ receptor $(A v p r 1 b)$ gene and the adenosine $A_{1}$ receptor $\left(A_{1} R\right)$ are correlated with powerful and selective effects on the synaptic physiology of SC inputs to area CA2. Preliminary evidence has been presented showing that pharmacological activation in vitro of receptors for the social neuropeptides oxytocin and vasopressin (specifically Avpr1b) readily induces a long-lasting potentiation of synaptic transmission in area CA2 (Zhao and Dudek 2010: Zhao et al. 2011). Additionally, a recent report presents evidence that the high expression of $\mathrm{A}_{1}$ Rs in area CA2 (Ochiishi et al. 1999) is associated with persistent changes in synaptic efficacy in SC inputs to CA2 in response to $A_{1} R$ antagonists, including caffeine (Simons et al. 2011).

Caffeine is a naturally occurring adenosine receptor antagonist that is known to act on $\mathrm{A}_{1}$ Rs located both centrally and peripherally (Daly 1982; Daly and Fredholm 1998). Its effects on blood flow, heart rate, and general cellular metabolism notwithstanding, caffeine is consumed the world over mainly for its ability to enhance both attention and cognition. Although caffeine is nonselective as an adenosine receptor antagonist, its primary mechanism of action on cognitive function is thought to be through blockade of $A_{1}$ Rs in the brain (Daly 1982; Choi et al. 1988; Deckert et al. 1993; Daly and Fredholm 1998). Undeniably, specific antagonists of $A_{1}$ Rs enhance the induction of activity-dependent LTP in the hippocampus (Arai and Lynch 1992), and adenosine, the natural agonist of the receptor, inhibits LTP induction and prevents its stabilization in area CA1 (Arai et al. 1990; Rex et al. 2009). Previous studies, however, focused exclusively on SC inputs to CA1 neurons, and only recently has the role of $\mathrm{A}_{1}$ Rs in area $\mathrm{CA} 2$ been examined in relation to caffeine-induced cognitive enhancement. Consistent with the enrichment of $A_{1}$ Rs in CA2, a brief 5-min application of a physiologically relevant concentration of caffeine or other selective $\mathrm{A}_{1} \mathrm{R}$ antagonist induced a lasting potentiation of synaptic transmission in CA2 (Fig. 3A), but not in areas CA1 or CA3 (Simons et al. 2011; CA1, Fig. 3D; CA3, Fig. 3E). Interestingly, the $\mathrm{A}_{1} \mathrm{R}$-mediated increase in synaptic efficacy was also accompanied by a coincident increase in the volume of spines on CA2 pyramidal neurons (Fig. 3B,C). Finally, caffeine administered orally to rats, in doses comparable to those consumed by humans, also potentiated basal synaptic transmission in area CA2 with no effect on synaptic responses in area CA1 (Fig. 3F-I). Thus, even when the brains were subsequently removed and prepared for in vitro electrophysiological recordings, the effects of caffeine were apparent. This study was the first to demonstrate a selective enhancement of basal synaptic responses at CA2 synapses in vitro following oral administration of physiologically relevant doses of caffeine in vivo.

Consistent with the finding that calcium levels are severely restricted in CA2 pyramidal cells, there is no evidence that calcium-dependent pathways are required for the $\mathrm{A}_{1} \mathrm{R}$-mediated potentiation observed in CA2 (Simons et al. 2011). Instead, the potentiation is sensitive to inhibitors of adenylyl cyclase or protein kinase A, which is suggested by the enrichment of the calcium-independent adenylyl cyclases 5 and 6 present in CA2 (Visel et al. 2006; Lein et al. 2007). Thus, endogenous adenosine and physiologically relevant concentrations of caffeine are likely to play an important role in regulating synaptic activity in CA2 to modulate cognitive function. Moreover, these results also provide further evidence that CA2 is a distinct module of the hippocampal circuit with unique cellular properties.

\section{Role for CA2 in learning and memory}

Information transfer through the hippocampal circuit is critical for the formation of new memories. The finding that LTP is not normally expressed in SC inputs to CA2 suggests, however, that either the SC to CA2 pathway is a stable component of the hippocampal trisynaptic circuit not required for memory formation or that memories requiring the SC to CA2 pathway can be formed only under very specific conditions. Consistent with the latter possibility and as noted above, several stimuli, including vasopressin and caffeine, are capable of potentiating SC synapses in CA2 (Zhao and Dudek 2010; Simons et al. 2011; Zhao et al. 2011). Given that both caffeine and vasopressin influence social behavior (Wersinger et al. 2002; Prediger and Takahashi 2005; DeVito et al. 2009), we support the proposal of DeVito et al. (2009) that regulation of plasticity at CA2 synapses may play a role in some forms of social memory, such as social recognition.

Although early reports suggested a diffuse distribution of $A v p r 1 b$ mRNA across many different brain areas (Barberis and Tribollet 1996; Vaccari et al. 1998; Hernando et al. 2001), a more recent mRNA expression study using probes directed to $5^{\prime}$ or $3^{\prime}$ untranslated regions of the Avpr $1 b$ mRNA showed that $A v p r 1 b$ is largely expressed in CA2 pyramidal neurons (Young et al. 2006; Fig. 4A), a pattern also demonstrated by the Allen Brain Institute (Lein et al. 2005, 2007). Therefore, investigations assessing the behavior of $A v p r 1 b$ KO mice during tests of hippocampus-dependent learning and memory may provide clues as to the role of CA2 in mnemonic function. Avpr1b $\mathrm{KO}$ mice have been shown to display normal sensorimotor processing and basal levels of exploratory behavior, including normal spatial memory (Wersinger et al. 2002), a function closely linked to the hippocampus and associated structures. Interestingly, Avpr $1 b \mathrm{KO}$ mice show significant impairments on tasks that assess social recognition memory (Wersinger et al. 2002; DeVito et al. 2009). In particular, when tested for overall levels of sociability, Avpr $1 b$ KO mice show no preference for a chamber containing another mouse vs. one which contained nothing at all. This is in contrast to wild-type littermates which display a strong preference for chambers containing familiar animals. Moreover, when tested for social novelty, Avpr1b KO mice fail to discriminate between novel and familiar mice, a discrimination that wild-type animals can make easily (DeVito et al. 2009; Fig. 4B). Taken together, these findings suggest that Avpr1b plays a critical role in mediating social memory.

The role of Avpr1b, and by extension, area CA2, in social behavior could have been predicted based on the long history of work supporting the role of vasopressin in social behavior (Lee et al. 2009). Unexpectedly, however, Avpr1b KO mice were reported to have impairments in memory for the temporal order of objects, as measured using the "what-where-when" task (Dere et al. 2005). Although Avpr1b KO mice could distinguish between objects they had explored previously and could remember where in the arena they had encountered certain objects, they were impaired in their ability to remember the temporal order in which objects were presented to them relative to wild-type controls (DeVito et al. 2009). As a follow-up experiment, the authors probed memory for temporal order using an object-trace-odor task. During the task, animals were trained to dig in a cup filled with scented sand only when the odor of the sand matched a specific target object that animals had encountered a few seconds earlier. Although wild-type mice learned such temporal associations, $A v p r 1 b$ KO mice did not; performance for these mice was at or below chance levels (DeVito et al. 2009). These findings indicated that $A v p r 1 b$ KO mice are impaired in memory for temporal order in addition to their deficits in social behavior. Furthermore, given 
A

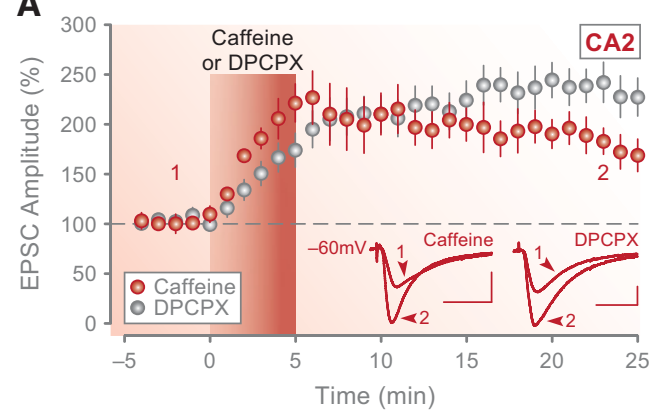

D

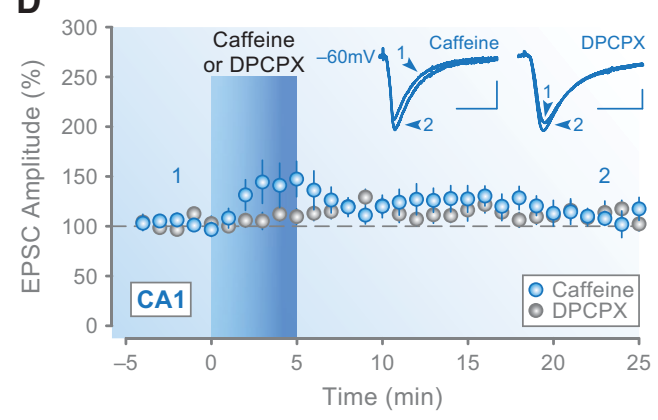

F Record in CA2

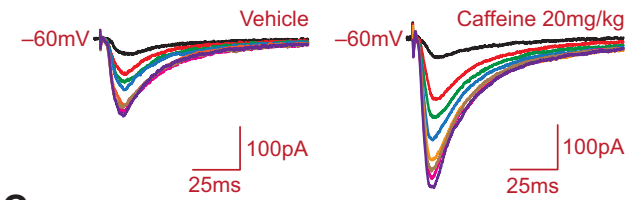

G

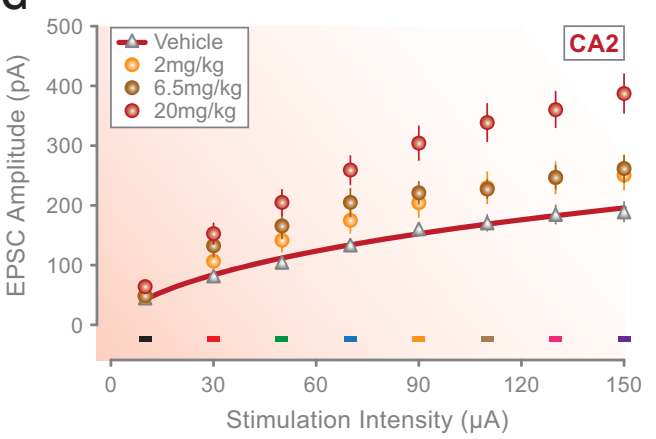

B
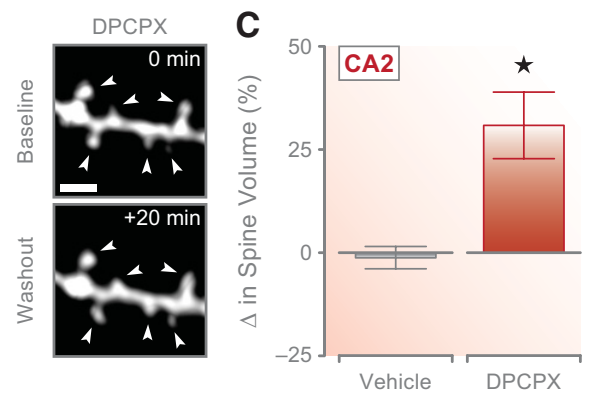

E

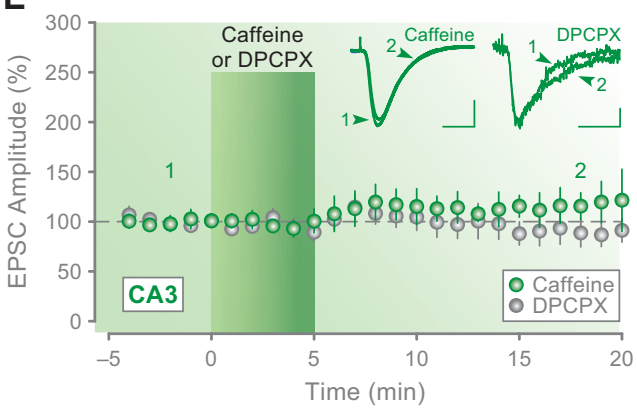

H Record in CA1

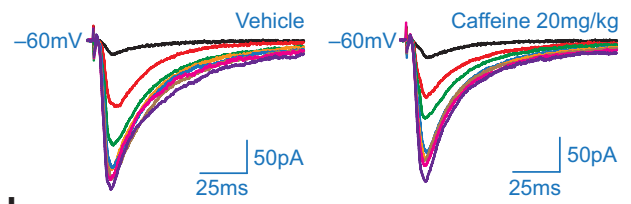

I

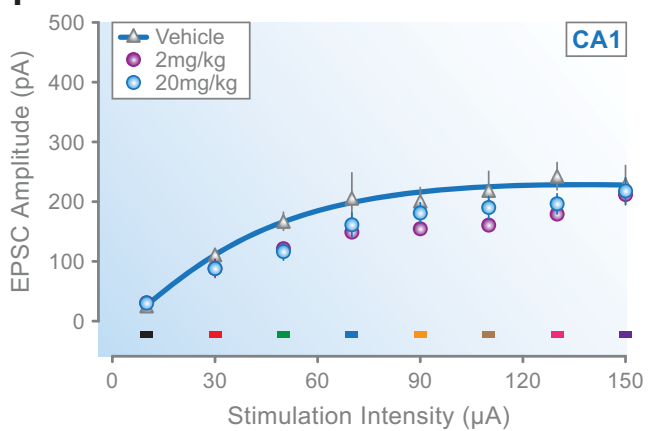

Figure 3. Blockade of $A_{1}$ receptors potentiates synaptic responses in CA2 but has no lasting effect on synaptic transmission in areas CA1 or CA3. (A) Bath-application of caffeine $(100 \mu \mathrm{M})$ or the selective $A_{1} R$ antagonist DPCPX $(10 \mathrm{nM})$ for 5 min potentiates synaptic responses in CA2. The red bar in $A$ marks the onset and duration of caffeine or DPCPX application, and the inset traces show example currents recorded at the latencies marked by the corresponding numbers. Brief exposure to DPCPX increases the volume of spines located on apical dendritic branches of CA2 pyramidal neurons. (B) Two-photon confocal images of a spine-containing segment of secondary apical dendrite for a CA2 neuron loaded with Alexa Fluor 594 are shown before ( $0 \mathrm{~min}$; baseline) and after ( $+20 \mathrm{~min}$; washout) 5 -min application of DPCPX $(10 \mathrm{nM})$. Arrows in $B$ mark spines that showed a significant change in volume after treatment with DPCPX (calibration bar $=1 \mu \mathrm{m})$. (C) Group data for all spines are shown comparing the average change in spine volume at 20-min post-vehicle or post-DPCPX treatment. There was no change in the amplitude of synaptic responses induced by caffeine or $\operatorname{DPCPX}(D)$ in areas CA1 or CA3 $(E)$. Conventions in $D$ and $E$ are the same as in $A$ (calibration bars for inset traces in $A, D$, and $E: 50 \mathrm{pA}, 25 \mathrm{msec}$ ). Caffeine consumption in vivo induces synaptic potentiation in hippocampal CA2 but not in CA1. $(F, G)$ Oral administration of caffeine induces a dosedependent increase in the amplitude of synaptic responses in CA2 in vitro across a range of stimulation intensities. $(H, I)$ Treatment with caffeine, however, had no effect on responses in CA1. Group data in $G$ and I show average synaptic responses at each stimulation intensity and dose of caffeine tested. Colored bars in $G$ and $I$ indicate the intensity used to evoke the corresponding colored currents in $F$ and $H$ from single neurons in slices from rats dosed with $20 \mathrm{mg} / \mathrm{kg}$ caffeine or vehicle (CA2, F; CA1, H). Data modified from Simons et al. (2011).

the apparent selective expression of $A v p r 1 b$ in CA2, these findings implicate CA2 in social memory and memory for temporal order.

Further insight into the function of CA2 may be gained by observing the behavior of mice with deletion of a specific gene in CA2, RGS14. As noted above, RGS14 is highly expressed in area CA2 (Fig. 4C), and deletion of RGS14 reveals a nascent ability to induce LTP in CA2 (Lee et al. 2010). Not surprisingly, therefore, RGS14 KO mice showed enhanced spatial learning when tested using the Morris water maze. Although the time required to locate a submerged hidden platform was similar for both wild-type and RGS14 KO mice on the first day of training, escape latencies were significantly faster on each successive training day for 
A

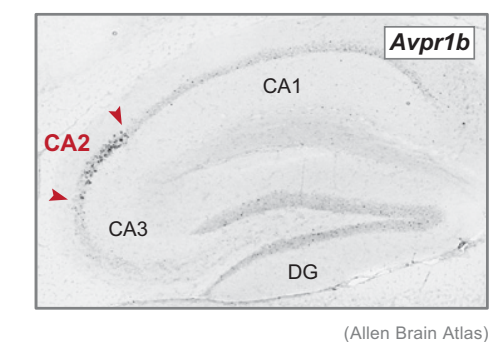

C

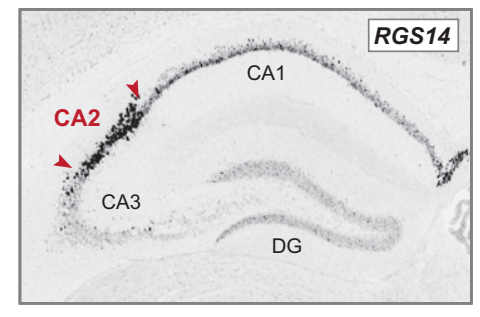

B

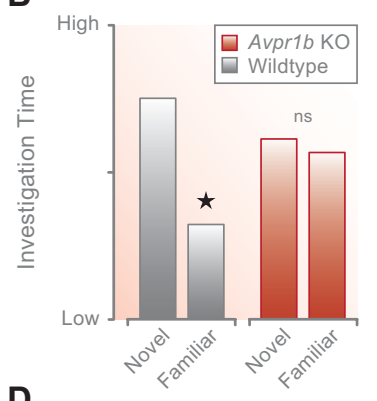

D

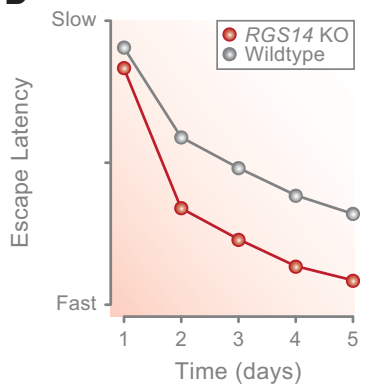

Figure 4. Expression of Avpr1b or RGS14 in hippocampal CA2 is linked to social recognition memory and spatial memory, respectively. $(A)$ The photomicrograph illustrates the high expression of the Avpr $1 b$ gene in area CA2 determined using in situ hybridization in a sagittal section of mouse brain. (Image source: Allen Brain Atlas, http://mouse.brain-map.org.) Arrows point to the borders between CA2 and adjacent areas CA3 and CA1. (B) Knockout of Avpr1b causes a deficit in social recognition memory. Wild-type mice spend significantly less time investigating a familiar littermate vs. a novel conspecific (gray bars). In contrast, Avpr $1 b$ KO mice spend the same amount of time investigating a familiar mouse as they do a novel one (red bars; ns = not significant). Data adapted from DeVito et al. (2009). Knockout of RGS14 in CA2 enhances spatial memory acquisition. (C) Photomicrograph shows the high expression of the RGS14 gene in CA2 using in situ hybridization (http://mouse.brain-map.org). (D) Mice lacking the full-length RGS14 protein learn the Morris water maze task faster than wild-type controls. Although similar on the first day of training, RGS14 KO mice (red circles) find the hidden platform significantly faster on subsequent training days relative to wild-type mice (gray circles). Data adapted from Lee et al. (2010).

RGS14 KO mice than for wild-type controls (Fig. 4D). Performance on subsequent probe trials conducted after training, however, was identical for RGS14 KO mice and controls, indicating that both groups of animals had, indeed, learned the task. In addition, RGS14 KO mice showed enhanced object recognition memory. Specifically, RGS14 KO mice could discriminate between a familiar object and a novel object significantly better than wild-type control animals. Based on the findings from both RGS14 KO mice and $A v p r 1 b$ KO mice, we hypothesize that area CA2 may play a significant role in social memory, object recognition memory and memory for temporal order.

A comparison of memory phenotypes for $A v p r 1 b$ KO mice and RGS14 KO mice raises an important question as to why Avpr1b KO mice show no deficit in spatial learning while RGS14 KO mice show enhanced spatial learning. Both the absence of RGS14 and the stimulation of Avpr1b permits induction of lasting plasticity at the SC synapse in CA2, suggesting that activation of Avpr $1 \mathrm{~b}$ and deletion of RGS14 would have similar effects on memory performance. One possible explanation is that the two proteins are differentially distributed between proximal and distal CA2 dendrites where the two primary glutamatergic inputs form synapses. However, the subcellular distribution of RGS14 and Avpr1b is currently unknown.

SC synapses are restricted mainly to the proximal dendrites of CA2 pyramidal cells, whereas afferents originating from the superficial layers of the entorhinal cortex contact the distal dendrites of CA2 neurons (Niimi et al. 2007; Nishimura-Akiyoshi the selective expression of tetanus toxin light chain (TeTX) show impairments in contextual fear conditioning and a reduction in the spatial tuning of CA1 place cells (Nakashiba et al. 2008). Interestingly, however, CA3-TeTX mice were still capable of forming some types of spatial memories. Thus, although CA3 inputs to CA1 assist in the spatial tuning of CA1 pyramidal neurons and are important for contextual fear conditioning, they are not critical for the spatial memory functions of the hippocampus. Nakashiba et al. (2008) speculated, based on these findings, that the temporoammonic input to CA1 was sufficient to support spatial memory formation in CA3-silenced mice. An alternative and, in our view, equally likely explanation is that CA2 provides an alternate route of information transfer, either as a compensatory mechanism or as a separate system that bypasses CA3 altogether (Chevaleyre and Siegelbaum 2010). Furthermore, lesion studies support this hypothesis (for review, see Jones and McHugh 2011).

Interestingly, CA2 is also a primary target of glutamatergic inputs originating from the hypothalamic SuM (Kocsis and Vertes 1994; Magloczky et al. 1994; Borhegyi and Leranth 1997; Pan and McNaughton 2004; Soussi et al. 2010). SuM activity has been shown to increase the frequency and amplitude of hippocampal $\theta$ oscillations (Vertes 1981; Kirk and McNaughton 1993; Oddie et al. 1994). Thus, decreased $\theta$ oscillation frequency and amplitude may partly explain the deficits in memory consolidation found upon inactivation of the SuM (Pan and McNaughton 1997; Shahidi et al. 2004a). In addition, SuM terminals express a number of neuroactive peptides, including cholecystokinin, 
substance-P, neuropeptide $\mathrm{Y}$, and vasoactive intestinal polypeptide (Greenwood et al. 1981; Gall and Selawski 1984; de Quidt and Emson 1986; Seroogy et al. 1988; Borhegyi and Leranth 1997), that may regulate synaptic transmission in CA2 in a manner similar to vasopressin or adenosine or modulate local inhibitory responses. Most notably, substance P-expressing SuM efferents target only CA2 in the rat (Borhegyi and Leranth 1997), and bath-applied substance $P$ has been shown to enhance synaptic responses in CA1 (Langosch et al. 2005). In addition, substance P increases GABA release by acting on neurokinin-1 receptors, thereby enhancing local inhibitory responses in the hippocampus (Ogier and Raggenbass 2003) and entorhinal cortex (Stacey et al. 2002). Interestingly, methods of inducing mild stress, such as exposure to an elevated plus maze (Silveira et al. 1993) or immobilization (Choi et al. 2012), have been shown to activate neurons in the SuM, presumably resulting in the release of substance P from SuM terminals in CA2. The effects of substance $\mathrm{P}$ on the physiology of CA2 pyramidal neurons are currently unknown.

The anatomical and physiological findings described above highlight the potential role of CA2 in cognitive and mnemonic function. Because CA2 receives afferent drive from both CA3 and the entorhinal cortex and has CA1 as its primary output, area CA2 has the potential to influence all forms of hippocampusdependent learning and memory. In addition, modulatory influences from the SuM may influence forms of memory related to stress.

\section{Area CA2 looking forward}

The hippocampus is undoubtedly one of the most widely studied anatomical structures in the mammalian brain, and there is little debate regarding its importance in mediating certain forms of learning, memory, and cognition. Nevertheless, despite advances in understanding area-specific function, only recently has the precise molecular delineation of the borders that divide various hippocampal subfields been described (Zhao et al. 2001; Lein et al. 2007). Because area CA2 has been largely overlooked when compared to neighboring regions, it remains a poorly understood component of the hippocampal circuit. Based on the unique physiology and connectivity inherent to area CA2, it is becoming increasingly clear that many current theories of hippocampal function will need to be revisited to account for the potential impact of area CA2 on certain forms of hippocampus-dependent learning and memory. Throughout this review, we have highlighted a number of ways that CA2 differs from other subfields in the hippocampus. In our view, SC synapses in CA2 may resist induction of canonical activity-dependent LTP in order to incorporate a number of atypical signaling molecules and modulatory systems required for optimal sensory and mnemonic processing by the hippocampus.

Numerous parallels can be drawn between the plasticitylimiting molecules enriched in CA2 and those found in other plasticity-resistant regions of the brain. For example, a key component of the extracellular matrix, a chondroitin sulfate proteoglycan that increases during development and is regulated by visual experience (Lander et al. 1997), is highly enriched in CA2 (Bruckner et al. 2003). Interestingly, destruction of this matrix has been reported to "reactivate" plasticity at ages extending beyond most critical periods (Pizzorusso et al. 2006) and to increase dendritic spine motility (Oray et al. 2004). Importantly, however, continued study of CA2 may also provide powerful insight into a diverse array of novel signaling molecules necessary to modulate the capacity for synaptic plasticity across different brain regions at different developmental stages.

\section{Acknowledgments}

This research was supported by the Intramural Research Program of the National Institutes of Health, National Institute of Environmental Health Sciences, Z01 ES 100221. We thank David Armstrong, Jerrel Yakel, and members of the Dudek lab for their input on earlier drafts of this manuscript.

\section{References}

Abraham WC, Williams JM. 2003. Properties and mechanisms of LTP maintenance. Neuroscientist 9: 463-474.

Arai A, Lynch G. 1992. Factors regulating the magnitude of long-term potentiation induced by $\theta$ pattern stimulation. Brain Res 598: 173-184.

Arai A, Kessler M, Lynch G. 1990. The effects of adenosine on the development of long-term potentiation. Neurosci Lett 199: 41-44.

Barberis C, Tribollet E. 1996. Vasopressin and oxytocin receptors in the central nervous system. Crit Rev Neurobiol 10: 119-154.

Barnes CA, Rao G, McNaughton BL. 1996. Functional integrity of NMDA-dependent LTP induction mechanisms across the lifespan of F-344 rats. Learn Mem 3: 124-137.

Bartesaghi R, Ravasi L. 1999. Pyramidal neuron types in field CA2 of the guinea pig. Brain Res Bull 50: 263-273.

Bliss TV, Lomo T. 1973. Long-lasting potentiation of synaptic transmission in the dentate area of the anaesthetized rabbit following stimulation of the perforant path. J Physiol (Lond) 232: 331-356.

Borhegyi Z, Leranth C. 1997. Substance P innervation of the rat hippocampal formation. J Comp Neurol 384: 41-58.

Boulanger LM, Lombroso PJ, Raghunathan A, During MJ, Wahle P, Naegele JR. 1995. Cellular and molecular characterization of a brain-enriched protein tyrosine phosphatase. J Neurosci 15: $1532-1544$.

Bruckner G, Grosche J, Hartlage-Rubsamen M, Schmidt S, Schachner M. 2003. Region and lamina-specific distribution of extracellular matrix proteoglycans, hyaluronan and tenascin-R in the mouse hippocampal formation. J Chem Neuroanat 26: 37-50.

Chevaleyre V, Siegelbaum SA. 2010. Strong CA2 pyramidal neuron synapses define a powerful disynaptic cortico-hippocampal loop. Neuron 66: 560-572.

Choi OH, Shamim MT, Padgett WL, Daly JW. 1988. Caffeine and theophylline analogues: Correlation of behavioral effects with activity as adenosine receptor antagonists and as phosphodiesterase inhibitors. Life Sci 43: 387-398.

Choi WK, Wirtshafter D, Park HJ, Lee MS, Her S, Shim I. 2012. The characteristics of supramammillary cells projecting to the hippocampus in stress response in the rat. Korean J Physiol Pharmacol 16: 17-24.

Crair MC, Malenka RC. 1995. A critical period for long-term potentiation at thalamocortical synapses. Nature 375: 325-328.

Daly JW. 1982. Adenosine receptors: Targets for future drugs. J Med Chem 25: $197-207$.

Daly JW, Fredholm BB. 1998. Caffeine-an atypical drug of dependence. Drug Alcohol Depend 51: 199-206.

de Quidt ME, Emson PC. 1986. Neuropeptide Y in the adrenal gland: Characterization, distribution and drug effects. Neuroscience 19: $1011-1022$

Deckert J, Berger W, Kleopa K, Heckers S, Ransmayr G, Heinsen H, Beckmann H, Riederer P. 1993. Adenosine A1 receptors in human hippocampus: Inhibition of [3H]8-cyclopentyl-1,3-dipropylxanthine binding by antagonist drugs. Neurosci Lett 150: 191-194.

Dere E, Huston JP, De Souza Silva MA. 2005. Episodic-like memory in mice: Simultaneous assessment of object, place and temporal order memory. Brain Res Brain Res Protoc 16: 10-19.

DeVito LM, Konigsberg R, Lykken C, Sauvage M, Young WS, Eichenbaum H. 2009. Vasopressin $1 \mathrm{~b}$ receptor knock-out impairs memory for temporal order. J Neurosci 29: 2676-2683.

Dudek SM, Bear MF. 1992. Homosynaptic long-term depression in area CA1 of hippocampus and effects of N-methyl-D-aspartate receptor blockade. Proc Natl Acad Sci 89: 4363-4367.

Dudek SM, Bear MF. 1993. Bidirectional long-term modification of synaptic effectiveness in the adult and immature hippocampus. J Neurosci 13: $2910-2918$.

Dudek SM, Friedlander MJ. 1996. Developmental down-regulation of LTD in cortical layer IV and its independence of modulation by inhibition. Neuron 16: 1097-1106.

Feldman DE. 2000. Timing-based LTP and LTD at vertical inputs to layer II/ III pyramidal cells in rat barrel cortex. Neuron 27: 45-56.

Gall C, Selawski L. 1984. Supramammillary afferents to guinea pig hippocampus contain substance P-like immunoreactivity. Neurosci Lett 51: $171-176$.

Gerendasy D. 1999. Homeostatic tuning of $\mathrm{Ca} 2+$ signal transduction by members of the calpacitin protein family. J Neurosci Res 58: 107-119. 
Greenwood RS, Godar SE, Reaves TA Jr, Hayward JN. 1981. Cholecystokinin in hippocampal pathways. J Comp Neurol 203: 335-350.

Hendrickson AE, Van Brederode JF, Mulligan KA, Celio MR. 1991. Development of the calcium-binding protein parvalbumin and calbindin in monkey striate cortex. J Comp Neurol 307: 626-646.

Hernando F, Schoots O, Lolait SJ, Burbach JP. 2001. Immunohistochemical localization of the vasopressin $\mathrm{V} 1 \mathrm{~b}$ receptor in the rat brain and pituitary gland: Anatomical support for its involvement in the central effects of vasopressin. Endocrinology 142: 1659-1668.

Hooks BM, Chen C. 2007. Critical periods in the visual system: Changing views for a model of experience-dependent plasticity. Neuron 56: 312-326.

Hubel DH, Wiesel TN, LeVay S. 1977. Plasticity of ocular dominance columns in monkey striate cortex. Philos Trans R Soc Lond B Biol Sci 278: 377-409.

Ishizuka N, Cowan WM, Amaral DG. 1995. A quantitative analysis of the dendritic organization of pyramidal cells in the rat hippocampus. $J$ Comp Neurol 362: 17-45.

Jones MW, McHugh TJ. 2011. Updating hippocampal representations: CA2 joins the circuit. Trends Neurosci 34: 526-535.

Kirk IJ, McNaughton N. 1993. Mapping the differential effects of procaine on frequency and amplitude of reticularly elicited hippocampal rhythmical slow activity. Hippocampus 3: 517-525.

Kocsis B, Vertes RP. 1994. Characterization of neurons of the supramammillary nucleus and mammillary body that discharge rhythmically with the hippocampal $\theta$ rhythm in the rat. J Neurosci 14: $7040-7052$.

Kubota Y, Putkey JA, Shouval HZ, Waxham MN. 2008. IQ-motif proteins influence intracellular free $\mathrm{Ca} 2+$ in hippocampal neurons through their interactions with calmodulin. J Neurophysiol 99: 264-276.

Lander C, Kind P, Maleski M, Hockfield S. 1997. A family of activity-dependent neuronal cell-surface chondroitin sulfate proteoglycans in cat visual cortex. J Neurosci 17: 1928-1939.

Langosch JM, Kupferschmid S, Heinen M, Walden J, Herpfer I, Fiebich BL, Lieb K. 2005. Effects of substance P and its antagonist L-733060 on long term potentiation in guinea pig hippocampal slices. Prog Neuropsychopharmacol Biol Psychiatry 29: 315-319.

Lee HJ, Macbeth AH, Pagani JH, Young WS III. 2009. Oxytocin: The great facilitator of life. Prog Neurobiol 88: 127-151.

Lee SE, Simons SB, Heldt SA, Zhao M, Schroeder JP, Vellano CP, Cowan DP, Ramineni S, Yates CK, Feng Y, et al. 2010. RGS14 is a natural suppressor of both synaptic plasticity in CA2 neurons and hippocampal-based learning and memory. Proc Natl Acad Sci 107: 16994-16998.

Lein ES, Callaway EM, Albright TD, Gage FH. 2005. Redefining the boundaries of the hippocampal CA2 subfield in the mouse using gene expression and 3-dimensional reconstruction. J Comp Neurol 485: $1-10$.

Lein ES, Hawrylycz MJ, Ao N, Ayres M, Bensinger A, Bernard A, Boe AF, Boguski M, Brockway KS, Byrnes EJ, et al. 2007. Genome-wide atlas of gene expression in the adult mouse brain. Nature 445: 168-176.

Leranth C, Ribak CE. 1991. Calcium-binding proteins are concentrated in the CA2 field of the monkey hippocampus: A possible key to this region's resistance to epileptic damage. Exp Brain Res 85: 129-136.

LeVay S, Wiesel TN, Hubel DH. 1980. The development of ocular dominance columns in normal and visually deprived monkeys. J Comp Neurol 191: 1-51.

Lisman JE. 2003. Long-term potentiation: Outstanding questions and attempted synthesis. Philos Trans R Soc Lond B Biol Sci 358: 829-842.

Lorente de Nó R. 1934. Studies on the structure of the cerebral cortex II. Continuation of the study of the Ammonic system. J Psychol Neurol 46: $113-177$.

Lynch G, Larson J, Kelso S, Barrionuevo G, Schottler F. 1983. Intracellular injections of EGTA block induction of hippocampal long-term potentiation. Nature 305: 719-721.

Magloczky Z, Acsady L, Freund TF. 1994. Principal cells are the postsynaptic targets of supramammillary afferents in the hippocampus of the rat. Hippocampus 4: 322-334.

Malenka RC, Bear MF. 2004. LTP and LTD: An embarrassment of riches. Neuron 44: $5-21$

Malenka RC, Kauer JA, Zucker RS, Nicoll RA. 1988. Postsynaptic calcium is sufficient for potentiation of hippocampal synaptic transmission. Science 242: 81-84.

Massey PV, Bashir ZI. 2007. Long-term depression: Multiple forms and implications for brain function. Trends Neurosci 30: 176-184.

Mercer A, Trigg HL, Thomson AM. 2007. Characterization of neurons in the CA2 subfield of the adult rat hippocampus. J Neurosci 27: 73297338.

Morris RG, Davis S, Butcher SP. 1990. Hippocampal synaptic plasticity and NMDA receptors: A role in information storage? Philos Trans $R$ Soc Lond B Biol Sci 329: 187-204.
Mower GD, Caplan CJ, Christen WG, Duffy FH. 1985. Dark rearing prolongs physiological but not anatomical plasticity of the cat visual cortex. J Comp Neurol 235: 448-466.

Nakashiba T, Young JZ, McHugh TJ, Buhl DL, Tonegawa S. 2008. Transgenic inhibition of synaptic transmission reveals role of CA3 output in hippocampal learning. Science 319: 1260-1264.

Niimi K, Nishimura-Akiyoshi S, Nakashiba T, Itohara S. 2007. Monoclonal antibodies discriminating netrin-G1 and netrin-G2 neuronal pathways. J Neuroimmunol 192: 99-104.

Nishimura-Akiyoshi S, Niimi K, Nakashiba T, Itohara S. 2007. Axonal netrin-Gs transneuronally determine lamina-specific subdendritic segments. Proc Natl Acad Sci 104: 14801-14806.

Ochiishi T, Saitoh Y, Yukawa A, Saji M, Ren Y, Shirao T, Miyamoto H, Nakata H, Sekino Y. 1999. High level of adenosine A1 receptor-like immunoreactivity in the CA2/CA3a region of the adult rat hippocampus. Neuroscience 93: 955-967.

Oddie SD, Bland BH, Colom LV, Vertes RP. 1994. The midline posterior hypothalamic region comprises a critical part of the ascending brainstem hippocampal synchronizing pathway. Hippocampus 4: $454-473$.

Ogier R, Raggenbass M. 2003. Action of tachykinins in the rat hippocampus: Modulation of inhibitory synaptic transmission. Eur $I$ Neurosci 17: 2639-2647.

Oray S, Majewska A, Sur M. 2004. Dendritic spine dynamics are regulated by monocular deprivation and extracellular matrix degradation. Neuron 44: 1021-1030.

Pan WX, McNaughton N. 1997. The medial supramammillary nucleus, spatial learning and the frequency of hippocampal theta activity. Brain Res 764: $101-108$

Pan WX, McNaughton N. 2004. The supramammillary area: Its organization, functions and relationship to the hippocampus. Prog Neurobiol 74: $127-166$.

Pelkey KA, Askalan R, Paul S, Kalia LV, Nguyen TH, Pitcher GM, Salter MW, Lombroso PJ. 2002. Tyrosine phosphatase STEP is a tonic brake on induction of long-term potentiation. Neuron 34: 127-138.

Piskorowski RA, Chevaleyre V. 2012. Synaptic integration by different dendritic compartments of hippocampal CA1 and CA2 pyramidal neurons. Cell Mol Life Sci 69: 75-88.

Pitkanen A, Amaral DG. 1993. Distribution of parvalbuminimmunoreactive cells and fibers in the monkey temporal lobe: The hippocampal formation. J Comp Neurol 331: 37-74.

Pizzorusso T, Medini P, Landi S, Baldini S, Berardi N, Maffei L. 2006. Structural and functional recovery from early monocular deprivation in adult rats. Proc Natl Acad Sci 103: 8517-8522.

Prediger RD, Takahashi RN. 2005. Modulation of short-term social memory in rats by adenosine $\mathrm{A} 1$ and $\mathrm{A}(2 \mathrm{~A})$ receptors. Neurosci Lett 376: $160-165$

Ramón y Cajal S. 1902. Sobre un ganglio especial de la corteza esfeno-occipital. Trab del Lab de invest Biol Univ Madrid 1: 189-201.

Rex CS, Chen LY, Sharma A, Liu J, Babayan AH, Gall CM, Lynch G. 2009. Different Rho GTPase-dependent signaling pathways initiate sequential steps in the consolidation of long-term potentiation. J Cell Biol 186: 85-97.

Scorza CA, Araujo BH, Leite LA, Torres LB, Otalora LF, Oliveira MS, Garrido-Sanabria ER, Cavalheiro EA. 2011. Morphological and electrophysiological properties of pyramidal-like neurons in the stratum oriens of Cornu ammonis 1 and Cornu ammonis 2 area of Proechimys. Neuroscience 177: 252-268.

Seroogy K, Tsuruo Y, Hokfelt T, Walsh J, Fahrenkrug J, Emson PC, Goldstein M. 1988. Further analysis of presence of peptides in dopamine neurons. Cholecystokinin, peptide histidine-isoleucine vasoactive intestinal polypeptide and substance $P$ in rat supramammillary region and mesencephalon. Exp Brain Res 72: $523-534$.

Shahidi S, Motamedi F, Bakeshloo SA, Taleghani BK. 2004a. The effect of reversible inactivation of the supramammillary nucleus on passive avoidance learning in rats. Behav Brain Res 152: 81-87.

Shahidi S, Motamedi F, Naghdi N. 2004b. Effect of reversible inactivation of the supramammillary nucleus on spatial learning and memory in rats. Brain Res 1026: $267-274$.

Shankar S, Teyler TJ, Robbins N. 1998. Aging differentially alters forms of long-term potentiation in rat hippocampal area CA1. J Neurophysiol 79: $334-341$.

Shu FJ, Ramineni S, Hepler JR. 2010. RGS14 is a multifunctional scaffold that integrates $\mathrm{G}$ protein and Ras/Raf MAPkinase signalling pathways. Cell Signal 22: 366-376.

Silveira MC, Sandner G, Graeff FG. 1993. Induction of Fos immunoreactivity in the brain by exposure to the elevated plus-maze. Behav Brain Res 56: 115-118.

Simons SB, Escobedo Y, Yasuda R, Dudek SM. 2009. Regional differences in hippocampal calcium handling provide a cellular mechanism for limiting plasticity. Proc Natl Acad Sci 106: 14080-14084. 
Simons SB, Caruana DA, Zhao M, Dudek SM. 2011. Caffeine-induced synaptic potentiation in hippocampal CA2 neurons. Nat Neurosci 15: $23-25$.

Sloviter RS. 1989. Calcium-binding protein (calbindin-D28k) and parvalbumin immunocytochemistry: Localization in the rat hippocampus with specific reference to the selective vulnerability of hippocampal neurons to seizure activity. J Comp Neurol 280: 183-196.

Soussi R, Zhang N, Tahtakran S, Houser CR, Esclapez M. 2010. Heterogeneity of the supramammillary-hippocampal pathways: Evidence for a unique GABAergic neurotransmitter phenotype and regional differences. Eur J Neurosci 32: 771-785.

Stacey AE, Woodhall GL, Jones RS. 2002. Activation of neurokinin-1 receptors promotes GABA release at synapses in the rat entorhinal cortex. Neuroscience 115: 575-586.

Stichel CC, Singer W, Heizmann CW, Norman AW. 1987. Immunohistochemical localization of calcium-binding proteins, parvalbumin and calbindin-D 28k, in the adult and developing visual cortex of cats: A light and electron microscopic study. J Comp Neurol 262: $563-577$.

Talley EM, Solorzano G, Lei Q, Kim D, Bayliss DA. 2001. CNS distribution of members of the two-pore-domain (KCNK) potassium channel family. $J$ Neurosci 21: 7491-7505.

Tamamaki N, Abe K, Nojyo Y. 1988. Three-dimensional analysis of the whole axonal arbors originating from single CA2 pyramidal neurons in the rat hippocampus with the aid of a computer graphic technique. Brain Res 452: 255-272.

Vaccari C, Lolait SJ, Ostrowski NL. 1998. Comparative distribution of vasopressin $\mathrm{V} 1 \mathrm{~b}$ and oxytocin receptor messenger ribonucleic acids in brain. Endocrinology 139: 5015-5033.

van Strien NM, Cappaert NL, Witter MP. 2009. The anatomy of memory: An interactive overview of the parahippocampal-hippocampal network. Nat Rev Neurosci 10: 272-282.

Vellano CP, Lee SE, Dudek SM, Hepler JR. 2011. RGS14 at the interface of hippocampal signaling and synaptic plasticity. Trends Pharmacol Sci 32: 666-674.

Vertes RP. 1981. An analysis of ascending brain stem systems involved in hippocampal synchronization and desynchronization. J Neurophysiol 46: $1140-1159$.
Visel A, Alvarez-Bolado G, Thaller C, Eichele G. 2006. Comprehensive analysis of the expression patterns of the adenylate cyclase gene family in the developing and adult mouse brain. J Comp Neurol 496: 684-697.

Wang XF, Daw NW. 2003. Long term potentiation varies with layer in rat visual cortex. Brain Res 989: 26-34.

Wersinger SR, Ginns EI, O'Carroll AM, Lolait SJ, Young WS. 2002. Vasopressin V1b receptor knockout reduces aggressive behavior in male mice. Mol Psychiatry 7: 975-984.

Wiesel TN, Hubel DH. 1965. Comparison of the effects of unilateral and bilateral eye closure on cortical unit responses in kittens. J Neurophysiol 28: $1029-1040$.

Woodhams PL, Celio MR, Ulfig N, Witter MP. 1993. Morphological and functional correlates of borders in the entorhinal cortex and hippocampus. Hippocampus 3: 303-312.

Young WS, Li J, Wersinger SR, Palkovits M. 2006. The vasopressin 1b receptor is prominent in the hippocampal area CA2 where it is unaffected by restraint stress or adrenalectomy. Neuroscience 143: 1031-1039.

Zhao X, Lein ES, He A, Smith SC, Aston C, Gage FH. 2001. Transcriptional profiling reveals strict boundaries between hippocampal subregions. $J$ Comp Neurol 441: 187-196.

Zhao M, Choi YS, Obrietan K, Dudek SM. 2007. Synaptic plasticity (and the lack thereof) in hippocampal CA2 neurons. J Neurosci 27: 12025-12032.

Zhao M, Dudek SM. 2010. Vasopressin induces synaptic potentiation in hippocampal CA2 neurons. In 2010 Neuroscience meeting planner, abstract program no. 550.7. Society for Neuroscience, San Diego, CA.

Zhao M, Young 3rd. WS3rd, Dudek SM. 2011. Oxytocin induces synaptic potentiation in hippocampal CA2 neurons. In 2011 Neuroscience meeting planner, abstract program no. 141.04. Society for Neuroscience, Washington, DC.

Ziai MR, Sangameswaran L, Hempstead JL, Danho W, Morgan JI. 1988. An immunochemical analysis of the distribution of a brain-specific polypeptide, PEP-19. J Neurochem 51: 1771-1776.

Received December 16, 2011; accepted in revised form May 30, 2012. 


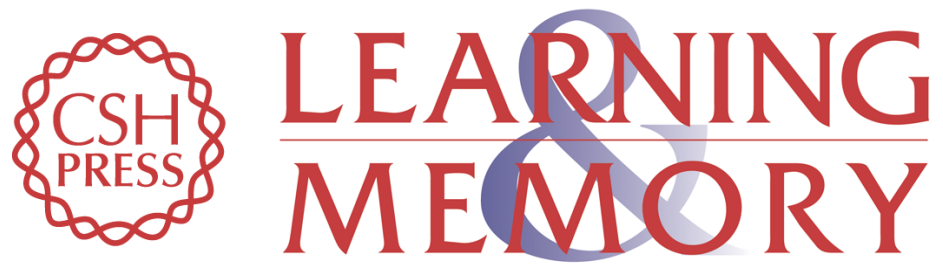

\section{New insights into the regulation of synaptic plasticity from an unexpected place: Hippocampal area CA2}

Douglas A. Caruana, Georgia M. Alexander and Serena M. Dudek

Learn. Mem. 2012, 19:

Access the most recent version at doi:10.1101/Im.025304.111

References This article cites 98 articles, 17 of which can be accessed free at:

http://learnmem.cshlp.org/content/19/9/391.full.html\#ref-list-1

License

Email Alerting Receive free email alerts when new articles cite this article - sign up in the box at the Service top right corner of the article or click here. 